\title{
The Politics Infiltrated with Arts: The Chinese Communist Party's Early Recognition and Emphasis on Revolutionary Ballads
}

\author{
Jie Chen \\ School of History, Zhengzhou University, Zhengzhou, Henan, China
}

Keywords: The Chinese Communist Party; propaganda; revolutionary ballads.

\begin{abstract}
The Chinese Communist Party paid great attention to propaganda work at the beginning of its establishment. In face of the low culture level of the broad masses of workers and peasants, how to transfer revolutionary ideas to ordinary people through effective means was the key to solve this propaganda dilemma. Under the influence of revolutionary songs of the Soviet Union, the early revolutionary intellectuals of Chinese Communist Party were keenly aware of the general public's preference to traditional ballads in the process of mobilizing the masses. By revolutionizing traditional songs, they derived revolutionary ballads, which were new forms of propaganda that conformed to the psychological cognition of ordinary people. Gradually, revolutionary ballads had been highly valued by the central committee of Chinese Communist Party. The central government issued documents to guide and promote this propaganda method to the party organizations all over the country, forming a nationwide organized and planned revolutionary ballads campaign.
\end{abstract}

\section{Introduction}

Traditional ballads are the product of the collective creation of the masses, which come into being naturally to satisfy the needs of the masses' living and production in the human history. However, until modern times, in the context of the international revolutionary thought spreading to China and the Chinese people trying to use the lower culture to innovate the upper culture, the new intellectuals paid great importance to the ballads of the traditional lower culture, among which the early Marxists led the songs to the politicized path under the influence of the Russian revolution. Since the Chinese Communist Party established, it had attached great importance to propaganda work, and politicized ballads had been frequently mentioned in central documents as important propaganda tools. This kind of propaganda influenced the whole country from top to bottom, forming an organized and planned revolutionary ballad campaign with clear guiding ideology.

\section{Propaganda Work of the Communist Party at the Initial Stage}

\subsection{The initial propaganda of the communist party}

The introduction of the October Revolution to China was a process of extensive publicity and dissemination in China under the theory of Marxism and its guidance. Under its influence, a large number of new intellectuals accepted Marxism and chose to follow the new path of saving the country. How could the Chinese Communist Party, as a revolutionary party founded with 53 members under the influence of the international revolutionary trend, expand the revolution to the whole country? The key factor was the expansion of their own strength and influence through propaganda. The Chinese Communist Party (CCP) established the central bureau on "the first national congress of Chinese Communist Party" and set up a propaganda department to coordinate the propaganda work of the whole party. The first resolution of Chinese Communist Party had a special chapter about "propaganda", which clearly stipulated the propaganda work of the party's early establishment, including the following two aspects: The first was about publicity, including books, daily newspapers, slogans and leaflets at the central level. At the same time, the local level included bulletin, daily, weekly, leaflet and circular. The second was to strengthen the party's propaganda work of supervision and leadership, ruled "whatever publications published by the central or local publishing work shall 
be affected by the leadership of the party members", and "no articles against the party's principles, policies or decisions can be published". Visibly, the propaganda work of Chinese Communist Party was a highly political work at the beginning of its establishment, which had strict organization and discipline. It was highly subject to policies and resolutions of the central committee of CCP and the propaganda publicity was diverse. However, it should be noted that the propaganda form of CCP was not static, but was highly targeted and adjusted to the change of its activity area and propaganda object.

The initial propaganda of the communist party was mainly aimed at intellectuals and workers who were inclined towards the revolution. The reason was that in the early stage of CCP, the main areas of activity were in important cities of China. The intellectuals and workers in these big cities had a certain degree of culture, and the propaganda mode was relatively moderate. With the further development of the "going to the folk" movement, especially during the northern expedition after the first Kuomintang-Communist cooperation, a large number of revolutionary intellectuals went to the countryside. Under this background, they faced a new revolutionary propaganda task aiming at the vast uneducated peasants. Therefore, the early propaganda mode was not suitable for the new propaganda object, which need resort to new forms to get out of the propaganda dilemma. Inspired by the revolutionary songs of Europe and Russia, as well as the personal feelings of the revolutionary intellectuals about the folk songs' popularity in the countryside, the revolutionary ballads were born. It was a propaganda form conforming to the cultural cognition of Chinese peasants. This new way of publicity gradually received high attention from the central committee of CCP and was emphasized in the central documents, which had a strong impetus for its popularization in the whole party.

\subsection{Revolutionary songs and the adjustment of propaganda strategy}

Revolutionary songs were not strange to CCP which was established by the influence of Russian October Revolution. With the participation and promotion of the early Marxists, there were revolutionary songs in the movement of Chinese workers before the founding of CCP. On May 1, 1920, the workers in Changxindian of Beijing hold a mass meeting under the influence of Marxist. They made speeches, and held a demonstration with 1500 workers taking part in. They "held up banners with important slogans, sang revolutionary songs, and marched through the streets shouting 'pay more, shorten working hours"'. The report on the workers' movement in Beijing came from a report by Zhang Guotao, who was a representative of the first congress of CCP. Slogans were prominent in the first resolution of CCP. On the contrary, revolutionary songs had not been taken seriously because they were not yet popular. However, early Marxists influenced by Russian revolution literature and art had realized the importance of popular literature, such as music and ballads, which were closest to the masses, and they begun to advocate in theory. In November 1921, Zhang Guotao, who went to Russia for the first time to participate in the people's congress of the Far East, felt the Russian revolutionary literary atmosphere in Irkutsk. He thought the highlight of the show, which held by the staff of the Far East every Saturday night, was the collective singing of revolutionary songs and the Caucasian dance. At the same time, he said, "Russian revolutionary songs with the characteristics of high pitch and strong vigor could stimulate human feelings." However, when delegates were invited to sing their own folk songs or revolutionary songs, the Chinese representatives did nothing, which made them deeply stimulated and felt the lack of collective entertainment in the Chinese revolution. "Later, the stimulus we received became a small starting point for the creation of Chinese revolutionary songs and the promotion of folk songs", Zhang said. In 1923, when Qu Qiubai who went to Russia many times studied the teaching plan of the department of arts in Shanghai University, he pointed out: "In fact, music and ballads are closest to the masses in art and beneficial to society. In China's current cultural level, it is especially necessary to promote the reorganization". The actual feelings and theories of the revolutionary literature and art had directly influenced the formulation and adjustment of the propaganda strategy of CCP with the deepening in the revolutionary practice of communist party.

\section{Peasant Movement and The Rise of Revolutionary Ballads}

During the northern expedition, the peasant movement developed gradually in the southern and 
central provinces of China, and the issue of peasant propaganda was included in the agenda of the propaganda work of CCP. In October 1925, the Resolution of Propaganda Issue, which was formulated by the central committee of CCP, gave detailed guidance on publicity strategies and forms. It pointed out that the propaganda of the workers and peasants "not only the language should be close to the masses, as well as the content. According to the reality of the workers and peasants, the most important thing of the agitation of the masses should be specific. Therefore, the communists should not only guide and train the masses, but also be able to examine the opinions of the masses, know their needs, and express their psychology through oral and literal propaganda". This shows that CCP had been aware of the opinions, needs and psychology of workers and peasants during the long term leadership of the workers' and peasants' movement. They formulated a targeted propaganda strategy in the propaganda resolution, and used the work of "editing popular pamphlet of songs and translating Marxist books" as "the fundamental role of propaganda and encouragement in words". It is obvious that it was the revolutionary songs which were already popular in the workers' movement that had attracted the attention of the central committee of CCP. They edited the songs so that they could be sung among the workers, but only in words, with limited scope.

With the deepening of the peasant movement and its expanding influence, in order to strengthen the guidance of the peasant movement, in July 1926, the central expanding executive committee of CCP specially formulated "the Resolution of Peasant Movement". The resolution presented a more targeted and operational approach to advocacy. It mainly included the following two aspects: First, it pointed out the basic principle of peasants' propaganda and agitation, that was, "all agitation and propaganda should be taken as the starting point of peasants' actual life suffering, and they should avoid extensive propaganda and mechanical lecture notes". Second, on the propaganda method, "posters, banners, ballads, slide and novel type of text expression should be fully used, so that we can attach our propaganda to change the village myth and legend, don't try to indoctrinate with an uninteresting, mechanical lecture". This was the first time that ballads appeared in the central committee of CCP's resolution, and pointed out the direction of propaganda by using ballads. The communist party's propaganda content were attached to the folk art forms such as ballads. In particular, it was worth noting that the promotion of content that reflected the actual suffering of peasants was more acceptable to the poor peasants than the mechanical and lecture notes. This was the direction for the later revolutionary adaptation of the country ballads.

\section{The Shift of Work Center and Emphasis on Revolutionary Ballads}

\subsection{The foundation of rural revolutionary bases}

After the collapse of the first Kuomintang-Communist cooperation in 1927, the power of CCP in the city was greatly weakened and it gradually turned its attention to the countryside. The August 7th meeting of CCP established the general policy of armed resistance to the Kuomintang and the agrarian revolution. The CCP turned its main positions of the upcoming activities to the vast rural areas, and stepped up to the road of the armed independent regime of workers and peasants. With the transfer of the revolutionary strategy to the rural areas, the work of CCP shifted to implement the political education that could captured the masses of workers and peasants, and the workers and peasants had become the main objects of propaganda work of CCP. The central committee of CCP had paid more attention to the effective forms of propaganda in the workers and peasants.

\subsection{The necessity and functions of revolutionary ballads}

In July 1928, the sixth national congress of CCP formulated the Present Task of Propaganda Work. The document believed that in the early period of transition to the countryside, the communist party's roots were not yet firmly established, and the white terror of the Kuomintang prevented the conditions of oral propaganda and incitement. Therefore, "various forms of publication propaganda (newspapers, leaflets, pamphlets, declarations, etc.) are of great significance." At the same time, the resolution stressed to use "various team, speaking class, self-study and other gathering of party organizations of various taught". In addition, the resolution also stressed that "we should issue and supply a large number of popular political books and newspapers in cities and villages, and pay attention to the poor workers and peasants. It is best to make them into ballads." In October of the same year, the central 
committee of CCP made a further statement on the propaganda work for rural and Soviet areas in Central Circular No. 4 -- on Propaganda and Agitation. The paper pointed out that in addition to using propaganda slogans, farmers, posters, congress, mass meeting, political speeches, schools, classes, newspapers and other propaganda ways, a different kind of propaganda way was particular emphasized, namely " transforming the slogans and policies of the communist party into ballads and folk songs". The folk song was a form of traditional Chinese ballad, and the central committee of CCP had explicitly proposed to transform the party's policy and slogan into folk songs, which was a revolutionary adaptation of traditional songs. This practice made the revolutionary path of traditional songs more obvious, and also pointed out the direction of the use of traditional ballads in the propaganda process of the party organizations in various Soviet areas.

The clear instructions of the central committee of CCP on the propaganda work in rural areas and soviet areas had a profound impact on the propaganda strategies and propaganda techniques of the party, government, and military organizations in each soviet areas. As a highly organized and disciplined Marxist political party, the CCP attached great importance to the effect of policy implementation from above to below. In order to effectively communicate the revolutionary principles, policies and strategies of the central committee of CCP, the central government sent inspectors to each soviet area to guide the revolutionary struggle and timely convey the central command. It was worth noting that the revolutionary ballads incorporated in the central propaganda policy were also conveyed to the soviet areas as a propaganda technique, which attracted the attention of the party, government, and military organizations in soviet areas. They responded to the central appeal actively, emphasized the importance of revolutionary ballads when making the resolution of propaganda work, formulated the creation and propaganda plan of revolutionary ballads according to the actual situation of local soviet area, revolutionized traditional ballads and used them in propaganda in an organized and planed way.

\section{Conclusion}

At the beginning of the revolution, the Chinese Communist Party did not consider revolutionary ballads as publicity means. But the CCP always stick to concrete analysis of concrete problems, and constantly change propaganda strategies according to actual situations. Compared with other publicity methods, ballades are easy to sing and remember, and can spread far, wide and fast. With the shift of work center and the foundation of rural revolutionary bases, traditional ballads with revolutionary lyrics gradually became important publicity methods.

\section{References}

[1] The central archives edited, The Selections of Documents of Chinese Communist Party Central Committee, 1921-1925, vol.1, Party School of the Central Committee of CCP Press, Beijing, 1989, pp. 6-7, pp. 14-19, p.26, p.209, p. 481.

[2] The central archives edited, The Selections of Documents of Chinese Communist Party Central Committee, 1928, vol.4, Party School of the Central Committee of CCP Press, Beijing, 1989, p.421, p.619.

[3] Zhang Guotao, My memory, Oriental publishing house, Beijing, 1998, vol.1, pp. 188-189.

[4] Qu Qiubai, The "Shanghai university" in modern China (July 23, 1923), Qu Qiubai vol.2, p.137. 